\title{
The Eye as a Mirror Not Only of the Soul, But of the Capillary Health
}

\author{
Diego Liberati* \\ National Research Council of Italy, Italy
}

*Corresponding author: Diego Liberati, National Research council of Italy, Milano Institute of Technology, Research Director for Information, Control and Biomedical Engineering, Milano, Lombardia, Italy

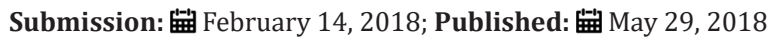

\section{Editorial}

A curious very infrequent pathology, Systemic Capillary Leakage Syndrome, induce the patient to dialyze his plasma through capillaries in a very massive way, at an opening let even albumine passing to the interstitial and lymphatic fluid even every less than a week. The monoclonal antibody spectrum of the episodic serum let understand a kind of autoimmune acquired syndrome. Being the period - even if the amplitudes are much bigger - analogous to the one perceivable in healthy fertile females in one half of the menstrual cycle, being the other half more resembling the healthy male in daily oscillations, a possible hypothesis of the pathogen could be a sexual hormone who has lost his standard cup vehiculating it through the blood to the target, where the cup should instead be removed to make its effect.

Deprivated of the protective cup, - like the ones in biotechnology we put on nano drugs in order to let them not be effective in transport, but just at target - the hormone could elicit the leakage with the dangerous effects. The eye is a perfect organ to let us study the capillaries in vivo in an almost non invasive way: a research proposal aiming at investigating SCLS with the purpose to understand and possibly to heal, should thus probably involve, besides weight oscillations or daily diuresis, analysis of fundus oculi as an immediate alert and maybe quantification of the event.

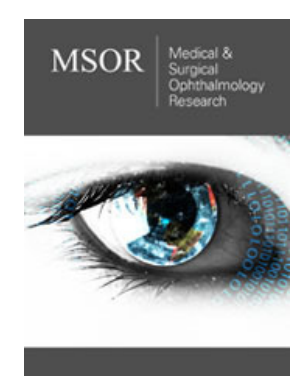

\section{Medical \& Surgical Ophthalmology Research} Benefits of Publishing with us

- High-level peer review and editorial services

- Freely accessible online immediately upon publication

- Authors retain the copyright to their work

- Licensing it under a Creative Commons license

- Visibility through different online platforms 